\title{
Educação e barbárie: aspectos culturais da violência na perspectiva da teoria crítica da sociedade
}

\author{
Sílvia Rosa Silva Zanolla \\ Doutora em Psicologia Escolar (Universidade de São Paulo) \\ Professora da Faculdade de Educação da Universidade Federal de Goiás \\ Goiânia, GO, Brasil \\ silviazanolla@hotmail.com
}

\begin{abstract}
Resumo Este trabalho se orientou pelos desafios impostos à escola e à educação, no sentido de combater a violência e a barbárie no aspecto amplo e cultural. Nesse sentido, as contribuições da teoria crítica da Escola de Frankfurt apresentam-se fundamentais para refletir sobre as (im) possibilidades do intento, em face das demandas por educação e tecnologia emergentes na sociedade atual.
\end{abstract}

Palavras-chave: teoria crítica, violência e infância; educação e sociologia.

E MBORA COMPLEXA E POLÊMICA, a teoria crítica da sociedade, abordagem referente aos estudos e pesquisas dos pensadores da Escola de Frankfurt (cf. Jay, 1973), tem como princípio claro a luta contra a violência e a barbárie no aspecto material e humano, fenômeno que perpassa a constituição da civilização desde os períodos que antecedem a sociedade moderna e contemporânea.

Para os frankfurtianos Adorno e Horkheimer (1985), essa luta não reside apenas no âmbito do universo objetivo e econômico, também é da ordem da cultura, apresentando um modelo político-estético, manifestado na exclusão e nas injustiças sociais permeadas pela subjetividade humana. Embora se utilizem de vários pensadores da teoria do conhecimento para sustentar esses argumentos, os autores elegem dois eixos teóricos principais: a psicanálise freudiana, como tentativa de compreender o aspecto subjetivo, e a sociologia marxiana, devido à importância desta para a compreensão dos fatores materiais de dominação que levam à manutenção do sistema capitalista (Zanolla, 2007a).

Concentrar-se na preocupação direcionada aos rumos da cultura e aos desafios à humanização na luta contra a violência e a barbárie tornase ponto basilar para a teoria crítica. A humanidade deve centrar seus esforços em promover estudos e pesquisas que investiguem o porquê de o conhecimento, a cultura e o desenvolvimento tecnológico, na maioria das vezes, não se fazer acompanhar pelo desenvolvimento verdadeiramente humano e autônomo, tanto no aspecto subjetivo quanto objetivo (Horkheimer e Adorno, 1985).

Essa visão ampla da violência encontra em Adorno (Adorno, 1995a) a tentativa de, segundo ele, superar a barbárie no sentido geral como condição para a sobrevivência da humanidade. Por isso postula o papel da educação como fator primordial para a sobrevivência da humanidade, tendo como base a formação cultural contra a ignorância e qualquer tipo de violência.

Adorno conceitua e identifica o sentido da barbárie em dois aspectos: objetivo, referente aos fatores e situações sociais que contribuem 
para a violência no âmbito estrutural, da ordem das relações produtivas e, nos aspectos humanos inerentes à constituição da subjetividade, o que envolve reconhecer fatores que dizem respeito à dinâmica psíquica dos indivíduos, à "sua alma", ou "espírito", no sentido filosófico da singularidade humana: seus desejos, necessidades, sentimentos e emoções.

Embora aqui se considere o aspecto objetivo, que diz respeito à abordagem marxiana, privilegiar-se-á a discussão referente a fatores subjetivos devido à delimitação em função do tempo e do recorte feito por mim. Isso se justifica tendo como meta a ideia defendida por Adorno (1995b) referente à necessidade do "segundo giro copernicano", em que defende, com base em Kant, estudos e pesquisas no sentido de compreender os embates ideológicos imanentes aos impeditivos (in)conscientes da humanidade a uma real e ampla revolução: política, econômica, cultural e humana. Assim, Adorno denuncia a própria idealização da práxis, o que, segundo ele, contraditoriamente leva tanto o sujeito quanto sua prática à fetichização e à coisificação.

Carece pontuar como base para a discussão os seguintes escritos de Freud: O mal-estar na cultura (1973a), Introdução ao narcisismo (1973c), Totem e tabu (1973d), Psicologia das massas e análise do ego (1973e) e O futuro de uma ilusão (1973b). Tendo como ponto de partida a leitura culturalista da psicanálise (Jay, 1973), apreende-se que, para Freud, o preço da cultura ou da educação é mais que castração ou interdição, é elaboração e renúncia. Não basta ao homem reprimir seus instintos mais agressivos, há que elaborá-los para que os sublimem sob a forma de atitudes aceitáveis socialmente (Freud, 1973a).

Por essa lógica, o homem nasce com o dilema de ter de enfrentar necessidades e desejos que jamais serão satisfeitos por completo, sob pena de não ser aceito socialmente. Sujeito da falta, este se depara com o conflito interno que envolve uma ambivalência: agressividade (instinto autodestrutivo e pulsão de morte) e cultura (autopreservação e pulsão de vida). Do reconhecimento da necessidade desse enfrentamento e de suas contradições dependerá a possibilidade de se manifestar humanamente e, consequentemente, tornar-se sujeito da cultura. Daí a ideia de que a sublimação representa a capacidade de o indivíduo canalizar suas energias mais agressivas e primárias para atividades culturais como a intelectualidade, as artes, a política e a educação (Freud, 1973a). Não obstante, esse processo não ocorre de maneira linear e automática, envolve uma dialética entre a satisfação (princípio do prazer) e a possibilidades de sublimação (princípio da realidade) (Freud, 1973a).

Assim, o perigo de uma espécie de pseudosublimação perpassa a relação entre o sujeito e suas possibilidades de uma real elaboração, o que Marcuse denomina dessublimação repressiva (Marcuse, 1967). Nesse processo, as contradições da própria educação precisariam ser reconhecidas de maneira consciente: sua idealização e sua otimização através de métodos e metodologias, inclusive aquelas justificadas pela práxis, podem levar a prática escolar à submissão da cultura pela fetichização e coisificação da teoria e da prática: "A consciência reificada não termina lá onde o conceito de reificação ocupa um lugar de honra" (Adorno, 1985, p. 64). Isso se percebe no pragmatismo tanto da experiência quanto dos conceitos e conteúdos (Adorno, 1970). A supervalorização de teorias construtivistas que versam sobre o desenvolvimento e a aprendizagem exemplifica isso (Zanolla, 2009). Sob esse prisma, a barbárie se desdobra em dois aspectos: prática regressiva à violência física, primitiva, reminiscências e atitudes primitivas ou primárias, e identificação com a violência a partir de objetivos que mitificam e regridem o sujeito em atitudes racionais. Apesar da divisão didática, os dois aspectos não estão necessariamente dissociados.

A violência se apresenta como a ignorância humana em todos os sentidos, inclusive por atitudes aparentemente racionais justificadas em nome da razão. Qualquer tipo de atitude agressiva torna-se barbárie se acontecer em nome do poder, do domínio e do interesse pessoal ou grupal desprovido de valores humanistas, como o investimento em pesquisas científicas para aumentar o poderio de armamento bélico ou atividades tecnológicas que não visam à emancipação e ao combate às injustiças sociais. Outro exemplo da ignorância em nome da razão está no incentivo à competição, como se esta fosse um comportamento saudável na sociedade. Dessa ideia desdobra-se outra defendida até mesmo por psicólogos, de que a violência faz parte do cotidiano infantil e, devido a esse aspecto, o sujeito saudável deve aprender a conviver com a violência, já que a agressividade é elemento inerente à constituição do ser humano (Jones, 2003).

Para Adorno (1995a), é preciso ensinar as crianças a se horrorizarem com a violência, para que esta seja banida de vez da sociedade e da cultura. Entretanto, na cultura, os próprios adultos idealizam a cultura e aceitam a dessublimação, falseando a barbárie no cotidiano, em sua racionalidade e ações.

\section{Entendendo a psicanálise na educação - diferenciando agressividade de violência}

Segundo Freud (1973a), pensar a agressividade é pensar a constituição da cultura, da educação, da sociedade e da civilização. Nesse aspecto, a agressi- 
vidade extrapola o sentido da violência. A agressividade diz respeito a um elemento primário, inerente ao ser humano e compõe a energia libidinal. Para compreender essa lógica, é necessário identificar a visão de homem na psicanálise. O sujeito da falta é movido por uma energia libidinal, que o acompanha em sua constituição humana (instintos primários), e a agressividade rege a necessidade de satisfação imediata (princípio do prazer). A violência é uma contingência da energia libidinal que retorna aos instintos agressivos sob a forma de razão. Para que o sujeito possa sublimar sua agressividade deverá reprimir seus instintos mais agressivos de satisfação imediata e, com isso, passar pelo teste da realidade, elaborar essa energia como possibilidade de ser aceito socialmente e adquirir cultura (princípio da realidade) (Freud, 1973a).

Dito de outra forma: não é aconselhável analisar o indivíduo e a cultura separados de sua base constitucional - a luta contra a tendência agressiva envolvendo a estrutura biológica e a interação social. Assim, a agressividade também compõe a constituição humana. O que significa isso diante das manifestações sociais? A subjetividade compõe e é composta pelas estruturas e instituições sociais, pois manifesta através destas a possibilidade material e espiritual de elaboração através da repressão dos instintos mais primários.

Tudo aquilo que diz respeito às ações e às atividades humanas reflete a maneira como o sujeito administra a própria agressividade, ou melhor, como a equilibra. Tanto a formação de valores quanto as realizações institucionais e materiais expressam a capacidade de sublimação do homem. Assim, das mais complexas descobertas à mais simples criação, apresenta-se uma luta interna entre a agressividade e a tentativa de sua superação, canalizando-a para atividades e atitudes consideradas mais humanas. Isso significa que a cultura é o termômetro que mede os limites toleráveis da agressividade para o que se entende por aceitação social. Por isso a dissolução do complexo de Édipo se torna tão importante para compreender o sujeito e seus dilemas referentes à aceitação e à adaptação social ou não. ${ }^{1}$

Essas ideias revelam as contradições e ambivalências tanto da cultura quanto da psique humana. Para entender sua dinâmica, não se pode simplificar uma lógica tão complexa como a humana. Freud não está biologizando o homem, embora haja críticas nesse sentido. Apresenta a contradição e o conflito psíquico como motor da dialética da existência humana entre objetividade e subjetividade. Se a cultura reflete a educação de um povo, pressuposto aceito em nossa abordagem, então a agressividade permeia não apenas atos violentos como também consubstancia atitudes consideradas aceitáveis socialmente.

Por essa afirmação, se pode compreender a polêmica levantada por Freud, que assegura ser impossível, para a psicanálise, haver uma verdadeira educação (Kupfer, 1995). Essa impossibilidade está no fato de que o sujeito sempre precisará administrar a ambivalência morte versus vida, agressividade versus cultura, sem que com isso possa idealizar a educação. O processo educativo não é uma realização acaba$\mathrm{da}$, definitiva, idealizada. Isso exige reconhecer que a própria educação, ao invés de formar, poderia deformar mentalidades. Daí a ideia de que é preciso que o sujeito esteja atento quanto às próprias possibilidades de deformar a realidade a partir da razão e assim agindo, compreender que a mediação objetifica a realidade (Zanolla, 2007b). O dilema reflete ao mesmo tempo uma necessidade de desmistificar a cultura e a educação, enquanto pontua uma diferença entre violência e agressividade. Não obstante, deve reconhecer que isso custa muito caro aos indivíduos que se dizem muito civilizados e orientados pela práxis idealizada.

Devido a esse conflito, Freud (1973a) mantém a dialética psicanalítica na obra $O$ mal-estar na cultura (1929), não define radicalmente os conceitos de pulsão e instinto e trabalha com a definição de "instintos pulsionais". Por esse prisma, a barbárie não é um conceito que se limita à violência no aspecto físico, embora esse aspecto faça parte dela. A violência é postulada como um problema a ser superado, condição decisiva para a sobrevivência humana.

Agora, creio, o sentido da evolução cultural não nos resulta impenetrável: por força deve apresentar-nos a luta entre Eros e morte, instinto de vida e instinto de destruição, tal como se leva a cabo na espécie humana. Esta luta é, em suma, o conteúdo essencial dela mesma e, por isso, a evolução cultural pode ser definida brevemente como a luta da espécie humana pela vida. (Freud, 1973a, p. 3053)

O que para Freud constitui luta entre instintos agressivos e pulsões sublimadas não é diferente para Adorno (1995a) no que se refere à luta entre barbárie e esclarecimento. O conflito resume a eterna luta entre titãs (Eros e Tânatos, vida e morte), entre as possibilidades de constituição da verdadeira e humana 
educação diante das contradições da própria cultura, que, idealizada, protela sua realização. Essa idealização parte também da escola, considerada o locus máximo de produção da cultura.

A sociedade costuma cobrar da escola aquilo que é responsabilidade geral das instituições: a formação do indivíduo. Exige-se que se preste contas do desenvolvimento tecnológico e cultural. Não se percebe muitas vezes que o problema da violência vai além da escola. O desenvolvimento tecnológico e cultural é reflexo da interação do indivíduo com as mais variadas instituições e envolve condições materiais e humanas. Assim, a capacidade de combater a barbárie e educar não depende apenas das condições oferecidas pela escola, assim como a luta contra a violência não deve ser empreendida apenas a partir do espaço escolar. Tanto a formação humana quanto o comportamento violento são fenômenos construídos socialmente e como tal devem ser reconhecidos.

$O$ preconceito e a intolerância não serão combatidos na infância enquanto se manifestam nos brinquedos e brincadeiras infantis (armas, jogos extremamente competitivos e violentos, bonecas que apresentam um estereótipo que leva crianças a buscarem um padrão rígido de beleza, como a boneca Barbie, são exemplos).

Para Adorno (1995a), não há alternativa à sociedade humana e justa sem que as pessoas comecem a ser completamente tomadas pela aversão à violência (p. 165). Assim, a agressividade faz parte do cotidiano, mas sua banalização não deveria fazer. Cabe à educação fazer uma reflexão sobre as manifestações e contradições da experiência humana a partir do trabalho escolar. Inclusive no que diz respeito às atividades consideradas desportivas e artísticas, por mais que isso faça brotar as contradições dessa realidade.

Tal esforço reflete o combate à banalização da violência e reporta-se ao psicanalista infantil Bettheim (1987), para quem o conflito entre o certo e o errado nas brincadeiras contempla o direito às escolhas que a criança tem de fazer, como nas brincadeiras de mocinho e bandido; o mal e o bem se confrontam como possibilidade de referência e identificação com valores sociais. Processo que tende a ser esquecido nas brincadeiras atuais como no jogo eletrônico, no qual se percebe que as crianças se identificam mais com aqueles personagens mais fortes e que possuem armas mais poderosas e letais, ou melhor, aqueles que matam mais (Zanolla e Sousa, 1999).

O que se precisa estudar é de que maneira as estórias são processadas pela criança, fazendo com que assimile comportamentos trazidos por valores apreendidos culturalmente e, a partir disso, como se co- difica a questão da violência desse conteúdo também no aspecto objetivo. ${ }^{2}$ Isso poderia confirmar ou não se, nesse universo, a satisfação dos desejos coaduna-se com a violência a partir da diversão agressiva, favorecendo a banalização da barbárie.

Ao que parece, a banalização da violência implica a banalização dos afetos e dos sentimentos, sobretudo do medo. Na violência como espetáculo, o medo torna-se ausente na falta de conexão com o sentimento de perplexidade diante da morte, tornando-a sem valor. Supostamente, ocorre uma indiferença em relação à morte. $\mathrm{O}$ que favorece a frieza humana, pelo hábito de conviver pacificamente com a violência. $\mathrm{O}$ afeto se torna ausente pela repetição compulsiva da violência, levando a criança à adaptação, à frieza.

Adorno (1995a) se manifesta sobre a frieza que assola a sociedade moderna. Apresenta o perigo da indiferença humana em relação à dor alheia. Para o autor, a única forma de romper com a barbárie seria uma profunda mudança na estrutura social que possibilitasse ensinar às crianças a se horrorizarem com a violência e a miséria humana. Ao negligenciar esses perigos, o homem banaliza seus sentimentos e ansiedades. Instala-se a frieza com naturalidade. É preciso pesquisar nos mecanismos subjetivos, nos sentimentos e desejos as causas dessa indiferença:

Se alguma coisa pode ajudar contra a frieza como condição da desgraça, seria o entendimento das próprias condições que a causam e a tentativa de combatê-las antes de tudo no contexto individual [...]. A primeira coisa a fazer seria, portanto, ajudar na conscientização da frieza em si e apurar os motivos que a ela levaram. (Adorno, 1995a, p. 121)

Essa preocupação leva em conta o universo da cultura infanto-juvenil também através da literatura. Teixeira (2000), psicanalista infantil, em sua obra Monstros \& cia, desenvolve análise mostrando que, ao desprover a criança do contato com o medo, correse o risco de incentivar uma espécie de horror esquizofrênico, insuportável, pela sua própria ausência, que imobiliza forças identificatórias. Para demonstrar isso, utiliza uma versão de Chapeuzinho Vermelho, o conto infantil de Guimarães Rosa denominado "Fita verde no cabelo":

Logo de início ficamos sabendo que o lobo mau está ausente da trama: "Daí, que, indo atravessar o bosque, viu só os lenhadores, que por lá lenharam; mas o lobo nenhum, nem desconhecido nem peludo. Pois os lenhadores tinham exterminado o lobo". O que não impedirá Fita Verde de invocá-lo desesperada- 
mente, no famoso questionário final (numa estonteante versão roseana) para fazer frente ao que aí se vislumbra de insuportável. Ei-lo:

- Vovozinha, que braços tão magros, os seus, e que mãos tão trementes!

- É porque não vou poder nunca mais te abraçar, minha neta... - a avó murmurou.

- Vovozinha, mas que lábios, ai, tão arrocheados!

- É porque não vou nunca mais poder te beijar, minha neta... - a avó suspirou.

- Vovozinha, e que olhos tão fundos e parados, nesse rosto encovado, pálido?

- É porque já não estou vendo, nunca mais, minha netinha... - a avó gemeu. Fita Verde mais se assustou, como se fosse ter juízo pela primeira vez. Gritou: Vovozinha, eu tenho medo do Lobo!...

Mas a avó não estava mais lá, sendo que demasiado ausente, a não ser pelo frio, triste e tão repentino corpo. (Teixeira apud Zanolla, 2007a, p. 1345)

Da ausência de objetos valorativos na estória de Fita Verde, emerge a reflexão acerca da importância das identificações culturais na infância. Combater a frieza, a indiferença em relação à violência, e sua banalização apresentada nas mais diferentes versões, é primordial (Teixeira apud Zanolla, 2007a). Para impedir a prevalência da perversão, versão subjetiva da barbárie, é preciso combater a frieza em favor do sentimento. Bem e mal são valores contraditórios, mas são importantes para que as crianças possam vivenciar e elaborar o medo como condição de sobrevivência social. Isso possibilita à criança lidar com a frustração e o limite diante da satisfação de necessidades ou da renúncia aos seus instintos mais agressivos.

Mais que combater a indiferença é necessário tentar responder como a criança e os jovens identificam o significado dos diferentes conteúdos, ou melhor, como se percebem na ausência de referências, desprovidas de conflitos valorativos.

Segundo Adorno, investir em pesquisas no universo cultural seria uma maneira de impedir que a barbárie se instale e, ainda, denunciar que os interesses pelo lucro no sistema capitalista abrangem a diversão e a educação, sobrepondo-se a qualquer forma de combater a ignorância. Não obstante, a escola deveria cobrar da grande indústria de videogame que abrisse mão do princípio lucrativo e investisse em jogos educativos contra a barbárie e a violência. "A desbarbarização da humanidade é o pressuposto imediato da sobrevivência. Este deve ser o objetivo da escola, por mais restritos que sejam seu alcance e suas possibilidades" (Adorno, 1995b, p. 117).

Entende-se que qualquer atividade, inclusive educacional, ao não assimilar a autocrítica, relativiza valores e ideais e apresenta efeitos regressivos à humanização. Conserva a dependência e a servidão, contribuindo para a ilusão de que é possível apreender, apenas no universo objetivo (econômico), instrumentos capazes de combater a dominação. A escola também reflete valores da indústria cultural. O espetáculo, efeito subjetivo produzido pela indústria cultural, constitui elemento de estímulo a interpretações extremistas - de um lado, a violência é tratada como elemento de dominação material e, de outro, torna-se meramente uma manifestação comportamental. Isso também leva à banalização. O espetáculo torna-se explicação racional. Objetivamente, justifica enganos que levam ao acirramento da crise de autoridade (falta de limite familiar, busca pelo apoio de autoridades externas à família como o Estado, toques de recolher e responsabilização da escola pela falta de disciplina).

Embora contraditória, a instituição familiar possibilita à criança elaborar valores e referências, e sua destituição leva à recaída, ao estado de ignorância e de agressividade humanas. A possibilidade de reversão do problema recai nas possibilidades de analisar o universo subjetivo. "Dado que a possibilidade de alterar os pressupostos objetivos - isto é, sociais e políticos - que contrariam tais resultados é hoje reduzida ao extremo, as tentativas de combate à reincidência desviamse necessariamente para o lado subjetivo" (Adorno, 1994, p. 34). A educação, apesar de ser contraditória, seria a única via capaz de oferecer possibilidades de autodesmistificação e rompimento com a barbárie. "A educação só teria pleno sentido como educação para a autorreflexão crítica" (Adorno, 1994, p. 35).

O problema da barbárie não é meramente subjetivista (1994, p. 43). Assim, há que se refletir sobre as contradições históricas da própria educação no sentido amplo, em relação ao seu trato específico com a violência. Para isso, é preciso reconhecer as contradições da educação como instrumento técnico de manutenção do capital, o que propicia uma análise mais aprofundada, menos idealizada. O assunto é tão complexo que a própria noção racional de contraposição à violência com base na bondade constitui falácia da indústria cultural:

Essa insistência sobre a bondade é a maneira pela qual a sociedade confessa o sofrimento que ela causa: todos sabem que não podem mais, neste sistema, ajudar-se a si mesmos, e é isso que a ideologia deve levar em conta. Muito longe de simplesmente encobrir o sofrimento sob o véu de uma camaradagem improvisada, a indústria cultural põe toda a honra da forma em encará-lo virilmente nos olhos e admiti-lo como uma fleuma difícil de admitir. O patos da frieza de ânimo justifica o mundo que a torna necessária. Assim, a vida é tão dura, por isso mesmo tão maravilhosa, tão sadia. (Horkheimer e Adorno, 1985, p. 141; grifo meu) 
A falsa ideia de felicidade que a indústria tenta passar é desmentida pela frieza predominante. Ocorre uma inversão de valores, o que viabiliza uma espécie de encantamento com o assistencialismo, confundido com solidariedade, assim como o amor se confunde com paixão e romance.

Para Adorno (1994), a situação de frieza na sociedade reside na incapacidade de identificação e de vinculação, vistos como causas que fizeram com que a barbárie se instalasse. A incapacidade de amar e ser generoso, diante da dominação e da ideologia, é a principal condição psicológica para que a violência e a barbárie se perpetuem. Assim, todas as pessoas hoje, sem qualquer exceção, sentem-se mal amadas, porque não são capazes de amar suficientemente. Mas a pior violência é o silêncio em face do terror da barbárie. Não calar seria fazer, diante da frieza crescente, uma demonstração de amor. Não o amor romântico, idealizado, idolatrado, não aquele ligado à felicidade momentânea, coisificado, mas o amor que possibilita outra estrutura social e de caráter: "Se alguma coisa pode ajudar contra a frieza como condição da desgraça, seria um entendimento das próprias condições que a causam e a tentativa de combatê-las antes de tudo no contexto individual" (Adorno, 1994, p. 43).

\section{Referências}

ADORNO, T. W. Educação e emancipação. Rio de Janeiro: Paz e Terra, 1995a.

ADORNO, T. W. Palavras e sinais - modelos críticos. Rio de Janeiro: Vozes, 1995b.

ADORNO, T. W. Sociologia. São Paulo: Ática, 1994.

ADORNO, T. W. Dialética negativa. Madrid: Taurus, 1970. BETTELHEIM, B. A psicanálise dos contos de fadas. Rio de Janeiro: Paz e Terra, 1987.

FREUD, S. O mal-estar na cultura. Obras completas. Madrid: Biblioteca Nueva, 1973a.

FREUD, S. O futuro de uma ilusão. Obras completas. Madrid: Biblioteca Nueva, 1973b.

FREUD, S. Introdução ao narcisismo. Obras completas. Madrid: Biblioteca Nueva, 1973c.

FREUD, S. Totem e tabu. Obras completas. Madrid: Biblioteca Nueva, 1973d.

FREUD, S. Psicologia das massas e análise do ego. Obras completas. Madrid, 1973e.

HORKHEIMER, M.; ADORNO, T. W. Dialética do esclarecimento. Rio de Janeiro: Zahar, 1985.

JAY, M. La imaginacion dialectica - história de la Escuela de Frankfurty el Instituto de Investigacion Social. Madrid: Taurus, 1973.

JONES, G. Brincando de matar monstros - porque as crianças
O calor humano seria uma alternativa à frieza, porém, no contexto, torna-se difícil incentivá-lo, já que mesmo os adultos, especificamente os pais, são produtos dessa inversão de valores. Muitas vezes a relação dos pais com os filhos é regida por valores capitalistas, fazendo com que confundam punição com limite, amor com recompensa, "O incentivo de dar mais calor humano aos filhos faz com que os pais funcionem artificialmente e, assim, esse calor acaba sendo negado" (Adorno, 1994, p. 44).

Isso pode ser exemplificado em casos em que os pais negociam sua ausência recompensando os filhos com objetos materiais. Se o problema persiste na sociedade como um todo, mais uma vez a esperança estaria na formação contra a barbárie desde a infância, na responsabilidade das instituições sociais, meios de comunicação, sobretudo, no fortalecimento do vínculo afetivo entre pais e filhos. Aos pais cabe assumirem o seu papel de autoridade e referência afetiva. À escola, cabe denunciar a barbárie em todas as suas nuances, desmistificar a si própria como instituição idealizada. Isso poderia contribuir em favor da elaboração subjetiva contra a perversão e a frieza do indivíduo na contemporaneidade, contra a violência e a ignorância nos seus variados desdobramentos.

precisam de fantasia, videogames e violência de faz-deconta. São Paulo: Conrad Editora do Brasil, 2003.

KUPFER, M. C. Freud e a educação. São Paulo: Scipione, 1995.

LAPLANCHE, Jean; PONTALIS, Jean Bertrand. Vocabulário de psicanálise. São Paulo: Martins Fontes, 1992.

MARCUSE, H. Eros e a civilização. Rio de Janeiro: Zahar, 1967.

TEIXEIRA, A. B. Monstros \& cia - a gênese do medo na literatura de horror e nos contos de fadas. Dos contos, em cantos. Salvador: Ágalma, 2000.

ZANOLLA, S. R. Jogos eletrônicos e massificação infantil uma análise da imposição e aceitação de valores culturais na infância à luz da teoria crítica. Projeto de pesquisa UFG, Goiânia, 2005.

ZANOLLA, S. R. Indústria cultural e infância: estudo sobre a formação de valores em crianças no universo do videogame. Revista Educação e Sociedade, v. 28, p. 13291350, São Paulo, set./dez. 2007a.

ZANOLLA, S. R. Teoria crítica e epistemologia. O método como conhecimento preliminar. Goiânia: UCG, 2007b.

ZANOLLA, S. R. Teoria crítica, cultura e educação. Educação, cultura e formação. O olhar da filosofia. Goiânia: Ed. PUC, 2009. 
ZANOLLA, S. R. O videogame no crepúsculo da educação: a produção de sentido na interface com a comunicação. Associação Nacional de Pesquisa em Educação (ANPED). Caxambu, GT 16, 2009b.
ZANOLLA, S.; SOUSA, L. A influência do videogame na formação de crianças de $3^{\mathrm{a}}$ a $4^{\mathrm{a}}$ séries - um estudo do jogo eletrônico enquanto mediação para a percepção infantil. Relatório Final Projeto Prolicen, UFG, Goiânia, 1999.

\title{
Educación y barbarie: aspectos culturales de la violencia en la perspectiva de la teoria crítica de la sociedad
}

\author{
Resumen \\ sociedad actual. \\ Palabras-clave: teoria crítica, violencia e infancia, educación y sociologia.
}

Este trabajo se detuvo en los desafios impuestos a la escuela y a la educación, en el sentido de combatir la violencia y la barbarie en el aspecto amplio y cultural. En este sentido, las contribuciones de la Teoria crítica de la Escuela de Frankfurt, se revelaron fundamentales para reflexionar sobre las (im) posibilidades de esta tentativa frente a las demandas por educación y tecnologia emergentes en la

\section{Education and barbarism: cultural aspects of violence in the perspective of critical theory of society}

\begin{abstract}
This work, whose main subject is oriented by challenges imposed by the school and education aiming to oppose the violence and barbarism in a wide and cultural aspect. So, the contributions of critical theory of Frankfurt School are fundamental to reflect about the possibility of (non) purpose, in face of the demands of education and emerging technology in the present society.
\end{abstract}

Key words: critical theory, violence and childhood, education and sociology 